\title{
Camestáo
}

\section{A competência transgressora dos contraespecialistas na produção de conhecimento socialmente orientado e no confronto de saberes}

\author{
Sonia Aguiar \\ Doutora, Universidade Federal de Sergipe, São Cristóvão, SE, Brasil; \\ saguiar@ufs.br
}

\begin{abstract}
Resumo: Uma literatura esparsamente desenvolvida desde os anos 1970, sobretudo no contexto europeu, discute a responsabilidade social dos cientistas e das instituições científicas frente a controvérsias que envolvem direitos humanos e situações de risco para os cidadãos. Com base nela, este artigo identifica instâncias e atores não formais de produção de conhecimento socialmente orientado e institucionalmente distribuído, que buscam influenciar os processos decisórios do Estado, do mercado e da sociedade com o apoio de mobilizações em rede, via tecnologias digitais. Tal opção é motivada pelo que propomos chamar de "ética do desvendamento e do confronto", associada ao que a socióloga da ciência suíça Helga Nowotny denomina "competência transgressora", típica dos contraespecialistas.
\end{abstract}

Palavras-chave: Contraespecialistas. Competência transgressora. Controvérsias científicas. Ética do desvendamento. Produção de conhecimento.

\section{Introdução}

Em suas investigações sobre os efeitos do uso das tecnologias digitais, Sandra Braman (2013, 2014) discute o engajamento de cientistas e técnicos na democratização dos processos decisórios relativos a governança, regulações e formulações de políticas públicas, que dependem de certas competências técnicas e epistemológicas. Seu foco de interesse centra-se nas relações entre cidadania, informação e ação em rede - que ela chama de network citizenship -, a partir de uma perspectiva jurídico-política que envolve setores governamentais e os sistemas institucionalizados de informação, ciência e tecnologia (C\&T) e pesquisa e desenvolvimento (P\&D).

Esta abordagem leva em conta, também, o escopo geográfico da rede e suas implicações geopolíticas, cuja territorialidade é definida por Braman (2013, p. 179) [...] “em termos do alcance da autoridade pública (jurisdição)" [...], 
como as controvérsias e os conflitos gerados pela internacionalização da Internet e a invasão de privacidade pelos sistemas de comunicação em rede (casos Wikileaks e Snowden, por exemplo). Já o "espaço cívico" define-se, para a autora (2013, p. 179), em função dos “[...] domínios nos quais indivíduos podem esperar ser capazes de exercer seus direitos e em relação aos quais têm responsabilidades".

Os estudos dessa autora estadunidense se desenvolvem nessa confluência entre as demandas da cidadania e a aplicação de conhecimento científico e competências técnicas em seu favor. Nesse sentido, dialogam com uma literatura que vem se desenvolvendo desde os anos 1970, ainda que esparsamente, por pesquisadores anglo-saxões e franceses preocupados com a responsabilidade social dos cientistas e das instituições científicas frente a controvérsias que envolvem direitos humanos e situações de risco para populações.

A maior parte dessa literatura diz respeito aos atores envolvidos com questões relacionadas aos dilemas ambientais contemporâneos, que exigem conhecimentos multidisciplinares e têm sido alvo de frequentes controvérsias científicas e políticas. E como tal, também se orientam pelos referenciais geográficos e de governança, nos quais se inscrevem os conflitos acerca dos conhecimentos que legitimam certas políticas públicas, ou as contestam.

A partir desses estudos, este artigo busca identificar instâncias e atores não formais de produção de conhecimento socialmente orientado e institucionalmente distribuído, baseado em um perfil de competência especializada (expertise) que busca influenciar os processos decisórios do Estado, do mercado e da sociedade (cidadãos, organizações, movimentos), com apoio de mobilizações em rede.

Parte-se da premissa de que não há discussão sobre poder, ética e democratização do conhecimento que possa deixar de fora os agentes dos sistemas de produção e distribuição de saberes - os cientistas, os técnicos, os especialistas, os intelectuais, os profissionais da informação, em seus diferentes contextos de atuação -, bem como os especialistas ativistas que atuam em espaços não legitimados pelas esferas formais de ciência e tecnologia. 
Esta abordagem tem origem nas reflexões apresentadas em tese de doutorado sobre informação e contrainformação nas redes de organizações nãogovernamentais (ONGs) e movimentos sociais (LOPES, 1996), desdobradas em dois outros artigos (AGUIAR, 2007a; 2008) ${ }^{1}$. Nesses estudos, foram identificados ativistas e profissionais que se contrapõem à "tecnocracia intelectual" e às "elites do conhecimento", em permanente tensão entre o saber teórico e o saber prático e orientados por problemáticas que afetam sujeitos e coletividades. Tal opção gnosiológica é motivada pelo que propomos chamar aqui de "ética do desvendamento e do confronto", associada ao que a socióloga da ciência suíça Helga Nowotny denomina "competência transgressora" (transgressive competence).

O desvendamento diz respeito à invisibilidade ou ocultamento de certas informações, de conhecimentos ou temáticas que exigem uma competência técnica e/ou cognitiva para que sejam publicizados. É tipicamente os casos do Wikileaks e das denúncias de Edward Snowden, mas também do esforço para tornar público e acessíveis temas "periféricos" ou negligenciados pela pesquisa científica, como a anemia falciforme, que durante muito tempo permaneceu ignorada pelo sistema dominante de saúde por ser "doença de negro e pobre"2.

O enfrentamento refere-se à mobilização necessária para dar suporte ao confronto com o establishment ou para garantir os processos de desvendamento, visando a transformações sociais, quebra de paradigmas ou mudanças nas relações de poder. É tipicamente o caso das redes de banimento do amianto e de combate à homofobia, que buscam desmontar construções discursivas e argumentações tecnocientíficas legitimadas pelo aparato do Estado.

Já a "competência transgressora" diz respeito não só à ultrapassagem das fronteiras disciplinares, mas também dos próprios limites teóricos, metodológicos e institucionais do conhecimento científico. Como observa Nowotny (2000, p. 13), a produção de conhecimento não se restringe mais à ciência praticada nas universidades e institutos de pesquisa, nem à tecnologia da indústria. Nem depende apenas “[...] de um tipo especial de instituição da qual se espera que o conhecimento transborde para o benefício de outros" (NOWOTNY, 2000, p. 13). Tanto em suas teorias e modelos quanto em seus 
métodos e técnicas, a produção de conhecimento "[...] tem se estendido do meio acadêmico para muitos tipos diferentes de instituições" (NOWOTNY, 2000, p. $13)$.

\section{0 interesse público da ciência}

A emergência de "competências transgressoras" está diretamente (mas não exclusivamente) relacionada às incertezas científicas e aos riscos sociais de campos controversos do conhecimento, como a energia nuclear, a engenharia genética, as biotecnologias agrícolas e as mudanças climáticas. Tais campos vêm sendo submetidos a intensos debates no contexto internacional provocados, sobretudo, pelas perguntas para as quais as ciências ainda não são capazes de dar respostas precisas, confiáveis e satisfatórias.

O enfraquecimento da crença na neutralidade científica e as críticas aos determinismos tecnológicos vêm sendo seguidos pela defesa de uma ciência independente dos interesses do Estado e do capital, sobretudo das grandes corporações que atuam globalmente, e de tecnologias orientadas por demandas sociais, em vez de exclusivamente pelo mercado. Nesse contexto, o que aparece em jogo é um confronto de conhecimentos construídos sob referências de mundo diferentes e cuja legitimação depende de escolhas políticas e/ou econômicas, e não meramente técnicas ou científicas: um confronto entre os especialistas do establishment e aqueles que se pautam por análises críticas, visões alternativas ou abordagens contra-hegemônicas (AGUIAR, 2007a).

Para Bourdieu (2004), todo campo é um campo de forças e de lutas para conservar ou transformar esse campo de forças, tanto em relação às pressões externas quanto às disputas internas, cada qual implicando mecanismos de resistência e de enfrentamento específicos, nos quais sempre entram em cena os problemas da autonomia e da legitimação. O primeiro diz respeito aos interesses, desejos e responsabilidades envolvidos em (ou esperados de) cada campo de atividades humanas, e ao grau de independência com que sujeitos e atores podem (ou dispõem-se a) assumi-los. O segundo refere-se à qualificação e à "autoridade" de quem formula, opina ou age publicamente. Para Bourdieu, a legitimação está associada à validação socialmente compartilhada das diferentes 
tomadas de posição; já para Habermas (1997) tem caráter fortemente normativo e dependente das instâncias deliberativas regulamentadas pelo Estado.

Ulrich Beck (2002, p. 117) alerta que o sistema normativo intermediado pelo Estado pode legitimar a imputabilidade de certos agentes, com base na ausência de conhecimento que permita estabelecer, com certeza, relações de causalidade dos riscos e das ameaças consumadas. Para ele, a funcionalidade política dos cálculos de risco leva à despolitização e à retirada da carga moral dos conflitos, pois é o próprio "[...] Estado que, na qualidade de agente, intermedeia as reivindicações das diversas partes em conflito [...]", fixando-as no sistema jurídico para dele extrair a legitimação que "[...] abranda o enorme potencial de conflito que há em tais riscos" (BECK, 2002, p. 117).

A tendência de utilização sistemática de conhecimentos especializados e competências técnicas em favor de demandas sociais começa a ser observada nos anos 1960, nos Estados Unidos (EUA) e na Europa, paralelamente à emergência de novos tipos de ações coletivas e à discussão sobre a ética na ciência. Palavras de ordem como advocacy ${ }^{3}$ e accountability ${ }^{4}$ passam a justificar o suporte técnico de especialistas a grupos de cidadãos e movimentos sociais para embargar projetos de grande impacto, como a construção de usinas nucleares ou de aeroportos em áreas densamente povoadas (NELKIN, 1981).

Essa ligação entre competência técnica e interesses de consumidores e usuários locais está na origem da ideia de "ciência cidadã" (citizen science), que surgiu nos EUA, nos anos 1970, a partir da abordagem de Ralph Nader sobre os direitos dos consumidores, que ele chamava de "interesse público da lei". Segundo Schneider (2002), a expressão foi adaptada por um grupo de físicos da Princeton University para "interesse público da ciência".

Ciência Cidadã pode ser definida como um esforço participativo e combinado de pesquisa, análise e educação pública que segue estritamente os princípios de empenho pelo bem-estar coletivo das atuais e futuras gerações de seres humanos de todo o planeta e da biosfera. $\mathrm{O}$ cientista cidadão, através de habilidades particulares de pesquisa e análise independentes, deve ajudar a proteger a sociedade dos padrões de desenvolvimento industrial, econômico e social que colocam os interesses do Estado ou das corporações acima dos benefícios coletivos sustentáveis. O Cientista Cidadão é o contraespecialista por excelência (SCHNEIDER, 2002, p. 2, grifo do autor) ${ }^{5}$. 
Nelkin (1975) observou que nas arenas sociopolíticas os cientistas desempenham um papel ambivalente: são ao mesmo tempo fundamentais e suspeitos, porque seu conhecimento é visto como fonte de poder. Esta contradição fica evidente nas controvérsias relacionadas aos cada vez mais complexos e abrangentes riscos ecológicos globais, que vêm sendo submetidos a um estratégico jogo de afirmação e negação, o qual expõe os limites, as incertezas e a suposta neutralidade da ciência, usada para justificar o "progresso" e ocultar das pessoas o conhecimento sobre o que as ameaça.

A exigência de um novo sentido para a relação ciência-sociedade aparece claramente no trato das questões do meio ambiente, já que as lutas ecopolíticas e socioambientais não podem prescindir de argumentos com alguma base tecnocientífica. Nesse campo, pesquisadores e ativistas lidam tanto com questões teóricas de fronteira das ciências ambientais quanto com desafios políticos e sociais cotidianos, o que os obriga a construir uma competência própria, diferenciada da de seus interlocutores acadêmicos, governamentais, empresariais e multilaterais.

Em extensa e consistente revisão de literatura produzida nas duas últimas décadas do século XX, Freitas e Porto (2004, p. 7) citam um texto de Jasanoff, publicado em 1993, para ressaltar a importância de não se separar o que se deseja conhecer acerca de um problema do que se pretenda fazer desse problema. Assim, os autores nos levam a pensar que o interesse público da ciência e o controle social sobre as tecnologias consideradas perigosas (incluindo sua recusa) dizem respeito a quem se visa "[...] proteger de determinados riscos, a que custo e deixando de lado que alternativas" (FREITAS; PORTO, 2004, p. 7).

Há, portanto, um embate entre uma ciência que dá respostas técnicas racionais "tranquilizadoras", normatizadas e "compensatórias" (via avaliação e gestão dos riscos), e um movimento interno e externo à comunidade científica de identificação e incorporação das demandas sociais, através de processos participativos. Ao refletir sobre "os usos sociais da ciência", Bourdieu (2004, p. 75) especulou: 


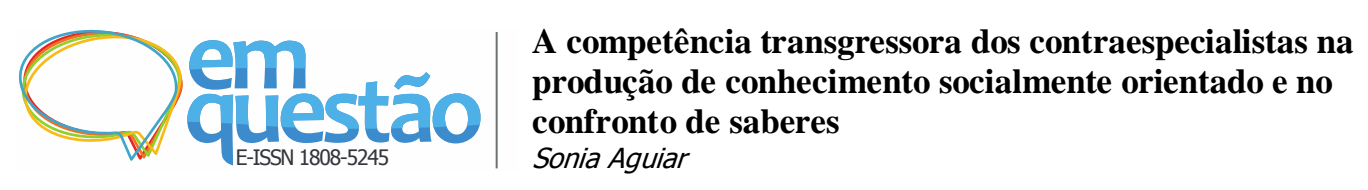

Se existisse uma estrutura de deliberação coletiva, capaz de ultrapassar as divisões [...] entre teóricos, práticos, básicos, aplicados, homens, mulheres e todo o resto, e que enunciasse as questões ao mesmo tempo importantes e urgentes, certamente isso seria uma boa coisa tanto para a ciência como para a sociedade.

Ainda segundo Bourdieu (2004), os cientistas e especialistas técnicos seriam continuamente desafiados pelo debate social e político a esclarecer certas questões, com base científica, e a definir temas e objetos de pesquisa a partir de uma sensibilidade em relação aos problemas que emergem da sociedade, os quais muitas vezes obrigam o pesquisador a sair dos limites do seu campo.

\section{Novos atores na comunidade científica}

Ensaios teóricos e estudos empíricos, sobretudo europeus, lançam mão de expressões como citizen scientist, independente scientist e civic expert para caracterizar uma mudança de atitude de parte da comunidade científica frente ao "interesse público da ciência", e uma nova relação da ciência com as questões societárias e sociopolíticas (FRANKEL, 1994; HANSEN, 2006; BIRD, 2014; RESNIK; ELLIOTT, 2016). Ou seja, uma "ciência socialmente responsável”, expressão também utilizada pelos autores de uma ampla pesquisa empírica realizada durante o $3^{\circ}$ Fórum Social Europeu (Londres, 2004), com base na metodologia da observação participante. Durante vários workshops e atividades culturais de alguma forma relacionadas às ciências em geral e à genética humana em particular, Welsh, Plows e Evans (2005) buscaram identificar as representações da ciência pelos atores do Fórum e sua utilização nas redes de ativismo global, bem como as ideias dos participantes sobre como criar uma ciência socialmente mais responsável e accountable.

Civic expertise é o termo usado por pesquisadores europeus que discutem a configuração de um modelo de competência técnica adequada à abordagem dos complexos problemas ambientais, em especial o desenvolvimento sustentável e os processos decisórios relativos aos riscos ambientais globais, necessariamente de caráter interdisciplinar. Em comum, eles têm a defesa de uma governança ambiental por meio de processos participativos que envolvam especialistas sensíveis às demandas dos cidadãos (civic expert) e 
não-especialistas capazes de formular essas demandas a partir das suas vivências cotidianas (no sentido expresso por Bourdieu). A premissa dessa linha de pensamento, partilhada por vários autores, é a de que conhecimento científico e saberes práticos são complementares e devem interagir para melhor qualificar a tomada de decisões (BRAND; KARVONEN, 2007; EDEN; DONALDSON; WALKER, 2006; NEVES-GRAÇA， 2006; BÄCKSTRAND， 2004; TATENHOVE; LEROY, 2003; WOODHOUSE; NIEUSMA, 2001).

Para a pesquisadora sueca Karin Bäckstrand (2004), essa “competência cívica" funciona como um campo intermediário nas avaliações críticas da ciência nas sociedades modernas, sustentado por uma abordagem pós-positivista do conhecimento científico, que visa dotar o trabalho científico de mais transparência, participação e democratização. Já para Brand e Karvonen (2007), as noções clássicas de competência técnica não dão conta dos dilemas do desenvolvimento sustentável, que só poderiam ser enfrentados por um "ecossistema" de quatro tipos de especialistas, cada qual com diferentes contribuições "em interação harmônica": os outreach experts - que no Brasil corresponderiam aos "educomunicadores" da ciência, por visarem manter o público cientificamente "alfabetizado" e criticamente informado; os interdisciplinares, que trabalham colaborativamente em um problema de interesse comum; os meta-especialistas, "generalistas" capazes de fazer avaliações transdisciplinares sobre problemas complexos; e os civic experts, que levam em conta o conhecimento empírico dos cidadãos e se comprometem com seus interesses no desenvolvimento científico e tecnológico.

O movimento por trás da ideia de outreach expert é o da "percepção pública da ciência", que visa: compreender a visão do público em geral acerca de questões científicas e tecnológicas; melhorar o entendimento coletivo sobre os seus aspectos relevantes; e "educar" os cidadãos com uma visão crítica sobre a primazia do conhecimento técnico nas decisões políticas e econômicas. Embora considerem a disseminação de conhecimento importante, Brand e Karvonen (2007, p.26) alertam para a insuficiência das iniciativas nessa área, em termos de reduzir as diferenças de poder entre especialistas e não- 
especialistas, ou de neutralizar o padrão modernizante de desenvolvimento científico e tecnológico.

Levada a extremo, a noção de especialista interdisciplinar favorece a emergência de uma nova classe de especialistas, que Brand e Karvonen (2007, p.27) rotulam de "meta-especialistas". Seu diferencial é o "ecletismo", isto é, a reconhecida capacidade de traduzir conhecimento transversalmente por diferentes clusters (agrupamentos) de especialistas, bem como de identificar potenciais ligações de sentido, de entrelaçar os diversos fios de pensamento para construir um "todo" e, assim, facilitar co-descobertas. Por isso são tipicamente identificados entre profissionais que trabalham com planejamento estratégico e formulação de políticas públicas, particularmente os sociólogos, antropólogos e geógrafos.

Para Brand e Karvonen (2007, p.29), porém, nenhum desses modelos anteriores ameaça o status privilegiado do conhecimento especializado ou dedica atenção significativa aos não-especialistas, cujo conhecimento emerge das práticas cotidianas, como propõem os civic experts. Estes defendem um processo participativo que envolva pesquisadores e cidadãos no planejamento de tecnologias e em empreendimentos transdisciplinares, não apenas para saber "como", mas também para questionar "por que".

Os autores reconhecem que essa proposta de construção de competência híbrida gera resistências, mas afirmam que formas mais democráticas de desenvolvimento tecnológico podem ser observadas em países que já possuem uma cultura política de participação cidadã nos processos decisórios, como Dinamarca, Holanda e Alemanha. No entanto, ressalvam que, mesmo nesses países, tais iniciativas ainda são exceção à regra, e demonstram que é preciso expandir o número de vozes nos processos de tomada de decisão sobre tecnologias.

A possibilidade de "desmonopolização" do saber especializado, a partir de uma estratégia de participação e pluralismo, a que se referem Freitas e Porto (2004), citando Beck e Giddens, abre espaço para a constituição de um novo sujeito sociopolítico, aqui denominado contraespecialista, que guarda estreita sintonia com os civic experts, mas deles se diferencia pelo papel que ocupa em 
uma sociedade como a brasileira, em que o exercício da cidadania ainda significa lutar por direitos fundamentais.

\section{Contraespecialista: um ator intercampos}

A expressão counter-expert foi, provavelmente, utilizada pela primeira vez nos Estados Unidos pela socióloga da ciência Dorothy Nelkin (1975, 1981), em referência aos cientistas e técnicos que assumem responsabilidades com movimentos comunitários e grupos de cidadãos. Eles empregam seus conhecimentos especializados e competências técnicas em favor das demandas sociais e em questões de controvérsias políticas envolvendo a aplicação de determinadas tecnologias ou procedimentos científicos.

Ao analisar os riscos como constructos sociais e como constructos cognitivos, Ulrich Beck (2002, 2009) refere-se aos contraespecialistas como uma categoria de ator que avaliza os movimentos sociais no confronto com especialistas do establishment, em relação ao conhecimento e à previsão dos riscos.

Isto inclui uma autocrítica involuntária da ciência no conflito entre especialistas e contraespecialistas, bem como a incapacidade de cumprir com antecedência promessas de segurança diante de 'desconhecimentos desconhecidos', e portanto da incapacidade de conhecer $^{6}$ (BECK, 2009, p.8).

O termo também foi utilizado por Habermas (1997) para indicar aquele que defende visões controversas no debate público, no contexto da ação comunicativa para formação da opinião pública. Helga Nowotny (2000) é mais estrita: chama de contraespecialistas aqueles que possuem um background científico, mas atuam abertamente como defensores de movimentos sociais e suas causas. Já Sezin Topçu (2008) considera que o termo contraespecialista (counter-expert) designa uma categoria de ator, enquanto counter-expertise refere-se a uma categoria de análise.

Assim, os contraespecialistas podem ser vistos como sujeitos sociopolíticos que transitam entre o campo das ciências, dos saberes e das técnicas (cf. Bourdieu), o "mundo da vida" e a "esfera pública política" (cf. Habermas), distinguindo-se e complementando-se nas arenas de lutas por suas 
trajetórias singulares. Uns provêm do campo acadêmico, correspondendo ao que Schneider (2002) identifica como "cientista-cidadão"; outros constroem seu perfil profissional a partir do ativismo em diferentes campos temáticos, como o ambiental, o da saúde, dos direitos humanos ou da democratização da comunicação.

Do ponto de vista da teoria dos campos de Bourdieu, contraespecialistas podem ser identificados como sujeitos que fazem mediações entre campos distintos, a partir da sua condição de pertencimento a um deles. O espaço social em que atuam pode ser caracterizado como um campo intercampos (as redes sociais, as instâncias de governança participativa, os projetos colaborativos, entre outros), com o objetivo declarado ou escamoteado de promover "subversões simbólicas", que exigem alto nível de capital cultural. Nessa perspectiva, aqui endossada, a posição de contraespecialista não é privilégio do intelectual ou do cientista, pois pode ser exercida por qualquer detentor(a) de saberes socialmente relevantes que possam ser confrontados com outros conhecimentos nas arenas de disputa.

É o que fica evidente na fala do líder seringueiro Osmarino Amâncio Rodrigues, durante sua participação como representante do Movimento dos Pequenos Agricultores do Acre na mesa-redonda Meio-Ambiente e Sociedade, na Reunião Regional da SBPC realizada na Universidade da Floresta ${ }^{7}$, em 2006. Morador da reserva extrativista Chico Mendes, Osmarino desafiou o discurso de engenheiros acadêmicos e governamentais ao rechaçar o manejo de madeira para exportação, defendendo técnicas de manejo que agreguem valor aos produtos não-madeireiros da floresta e o uso de tecnologias que consolidem as reservas extrativistas. Para ele, tanto o governo federal quanto o estadual "têm feito um discurso em que aceitaram a logística (sic) das madeireiras", como se falassem em nome dos extrativistas.

\footnotetext{
"Não foi essa nossa proposta. A gente só queria aproveitar a madeira caída pelo vento, pelos roçados de subsistência, não generalizar e semear plano de manejo madeireiro em todos os projetos de assentamento extrativista, PDS (Projeto de Desenvolvimento Sustentável), florestas estaduais, florestas públicas e agora reservas extrativistas", disse Osmarino.

[...] "Estão institucionalizando a depredação através dos decretos", assinala. "Isso não é sustentável, não garante o equilíbrio ecológico,
} 


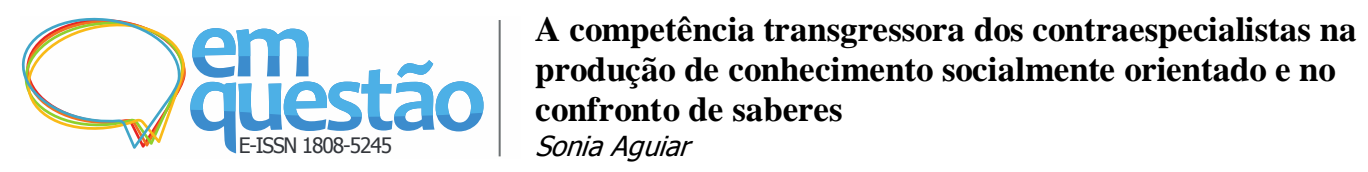

social e econômico. Muito pelo contrário, destrói a fonte de renda natural dessa região. Quando derrubam uma árvore grossa, perene, estão destruindo mais umas 50 espécies diferentes", disse o líder sindical (JC e-mail, 1/12/2006, apud AGUIAR, 2008, p.9-10).

Na sequência, Osmarino contestou os engenheiros florestais que dizem que isso degrada menos e que a espécie se recompõe em 30 anos:

Fizemos um estudo com o pessoal de Bruxelas, no Antimary ${ }^{8}$, que mostrou que o cumaru-ferro, que eles estão pagando $\mathrm{R} \$ 20$ por metro cúbico, tinha 800 anos. A árvore mais nova, a sumaúma, tinha 200 anos (AGUIAR, 2008, p. 10).

Para demonstrar o que dizia, o extrativista contou que 29 anos antes plantara algumas árvores, que ainda não haviam chegado a $10 \mathrm{~cm}$ de diâmetro. $\mathrm{O}$ confronto entre o conhecimento técnico especializado produzido no âmbito das instituições de pesquisa (sejam acadêmicas ou ONGs de assessoria) e o saber produzido na vivência das práticas locais (tradicionais ou inovadoras) pode, em determinadas circunstâncias, provocar um "choque epistemológico", como constataram Petersen e Almeida (2007, p.82) ao analisarem o desenvolvimento da Rede de Intercâmbio de Tecnologias Alternativas (Rede PTA) na década de 1980, embrião da Associação Nacional de Agroecologia.

A Rede PTA estabeleceu entre suas equipes locais e as entidades autônomas que dela faziam parte um fecundo processo de interação, voltado ao aprendizado mútuo sobre aspectos metodológicos, conceituais e técnicos do trabalho com agricultura alternativa. Além de uma crítica ao modelo da modernização agrícola, a Rede tinha em comum o fato de atuar de forma estreitamente vinculada a processos sociais locais, procurando difundir técnicas e métodos apropriados às situações específicas de inserção das famílias dos produtores.

A despeito da proximidade física com as famílias produtoras, o encontro das assessorias com as organizações de base se fez mediante um verdadeiro "choque epistemológico". Por mais comprometidas politicamente com o enfrentamento da problemática da "pequena produção", e por maior sensibilidade que tivessem em relação à importância da sabedoria popular, as equipes técnicas, compostas principalmente por profissionais egressos de cursos superiores e médios de ciências agrárias, haviam recebido uma formação acadêmica orientada para a expansão das formas capitalistas de produção no campo (PETERSEN; ALMEIDA, 2007, p. 81-82).

O papel dos contraespecialistas tem particular importância na formulação de demandas sociais ainda não explicitadas publicamente pelos que delas são 
sujeitos. "Há pessoas, no mundo social, que 'são faladas', por quem se fala, porque elas não falam, [e] para as quais se produzem problemas porque elas não os produzem.” (BOURDIEU, 2004, p. 83). Em Os usos sociais da ciência, o sociólogo chamou a atenção para a existência de pessoas que, em contrapartida, têm capacidades culturais e interesse para formular esse tipo de demanda, e considerou que estar atento a problemas que não chegaram a ser formulados deveria ser uma das responsabilidades dos cientistas.

Infelizmente, penso que há muito poucas demandas dirigidas aos cientistas e provenientes dos movimentos sociais, exceto o movimento ecológico que, por razões sociológicas, está em condições de fazê-las. De fato, é um movimento de pessoas dotadas de um alto nível de instrução cujo discurso empresta muito dos argumentos científicos (BOURDIEU, 2004, p. 81).

Assim, a configuração de uma counter-expertise - com toda a sua complexidade, heterogeneidade de atores sociais, peculiaridades geográficas, interesses difusos do Estado e do mercado - vem exigindo um intenso e rico processo de confronto e compartilhamento de saberes, referências culturais e formações ideológicas, fundamental para a construção dos contra-argumentos à racionalidade dominante, levados como posições da "sociedade civil" aos espaços participativos (que são também arenas de disputas discursivas e simbólicas).

\section{Da teoria à ação: os movimentos de contraespecialistas}

Em estudo sobre as transformações do papel da ciência e da competência técnica nos movimentos anti-nucleares franceses, entre os anos 1970 e 1990, Sezin Topçu (2008) identifica um movimento de contraespecialistas que para ela representa um fenômeno específico no interior do ativismo ambiental na era pós-Chernobyl. A iniciativa pioneira desse movimento foi a criação do Group of Scientists for Information on Nuclear Energy (GSIEN), logo após o lançamento, em 1974, pelo governo francês, de um programa de massificação da energia nuclear. Este incluiria a instalação de 170 reatores distribuídos por 40 localidades do país e elevaria a participação dessa fonte de energia para $85 \%$ até o ano 2000 (TOPÇU, 2008). A principal meta do Grupo era disseminar 
informação "objetiva" sobre a energia nuclear, contrapondo-se à informação oficial, considerada "enviesada" (TOPÇU, 2008, p. 230, aspas do original). No entanto, segundo Topçu (2008, p. 231), os membros do GSIEN não se identificavam como "contraespecialistas", nem mesmo como "especialistas" ou "experts":

Eles caracterizavam suas ações, antes de tudo, como 'cidadãos' que não tinham uma competência em relação ao programa de energia nuclear, mas eram capazes de ler e interpretar documentos técnicos e científicos por força da própria profissão de cientista (TOPÇU, 2008, p. 231).

A pesquisadora avalia que, ao empregar o conhecimento científico e desenvolver uma competência nas questões dos riscos socioambientais, o movimento de counter-expertise anti-nuclear contribuiu para o estabelecimento de um "contrapoder" (countervailing power).

No Brasil e em outros países da América Latina não foram encontrados estudos empíricos sobre essa categoria de ator "intercampos", mas há indícios de que esse papel de contraposição ao discurso oficial e a políticas governamentais em questões de interesse coletivo tem sido comumente exercido por organizações e movimentos sociais "leigos", com eventual participação de especialistas acadêmicos ou solidariedade pontual de entidades científicas.

Os breves estudos de casos apresentados a seguir, com base na metodologia de análise documental ${ }^{10}$, ilustram o potencial desse ator e indicam uma lacuna de estudos relevantes para ampliar o conhecimento sobre uma gama de conhecimentos, e de formas de conhecer, que representam um compromisso ético diferenciado daquele que vem sendo normatizado pelas instituições científicas tradicionais.

Esses modos "informais" de conhecer encontram ressonância no que Nowotny (2000, p. 15) qualifica como “[...] produção de conhecimento socialmente distribuído [...]", que implica uma crescente contextualização:

[...] as questões sobre as quais a expertise é demandada tornam-se cada vez menos uma escolha dos especialistas, mas são crescentemente direcionadas por uma audiência [audience-driven]. A dinâmica da produção de conhecimento socialmente distribuído repousa nos fluxos de conhecimento e nos padrões que compõem a conectividade entre esses fluxos. As conexões movem-se de acordo com o contexto do problema em vez de conforme as estruturas 
disciplinares ou as exigências da política científica nacional (NOWOTNY, 2000, p.14, tradução nossa).

Para Nowotny (2000, p. 14), o número de conexões vem aumentando, assim como cresce a importância de "fóruns híbridos", isto é, “[...] grupos constituídos a partir da interação de especialistas e leigos como atores sociais". Contudo, ao contrário do que ocorre no mundo das ciências, que celebram suas "excelências", observa-se em toda a literatura aqui trabalhada a ausência de atenção ao papel de alguns sujeitos que são centrais na constituição de certos campos de saber.

A história da constituição da Associação de Anemia Falciforme do Estado de São Paulo (AAFESP), bem como da incorporação dessa doença ${ }^{11}$ como objeto de atenção do Sistema Único de Saúde e de interesse acadêmico, no Brasil, especialmente na área de Enfermagem, parece ser indissociável da trajetória da enfermeira Berenice Assumpção Kikuchi. Foi ela que, em 1993, após atender uma criança de 10 anos recém-diagnosticada com anemia falciforme, em um posto de saúde de São Paulo, levou o caso para a Associação Afro-Brasileira OGBAN. Esta havia sido criada por profissionais da saúde e militantes do Movimento Negro da Região Leste da capital paulista, que tinham em comum “[...] a visão de que somente por meio da organização de uma entidade poderiam desenvolver ações dirigidas à atenção à saúde da população negra [...]", conforme a apresentação online da entidade.

A partir deste primeiro atendimento a OGBAN passou a acompanhar a trajetória dessa família na busca de assistência especializada. Este acompanhamento revelou nosso desconhecimento a respeito da enfermidade e, sobretudo, como o componente étnico poderia representar para estas famílias um somatório de estigmas, orientando uma nova militância para mobilizar vontades para a ação. Em busca de maior conhecimento técnico e científico recorremos ao Hemocentro de São Paulo, Fundação Pró-Sangue, no qual iniciamos um trabalho voluntário, voltado à Organização Social dos Doentes Falciforme no Município da São Paulo. Com base nesses encontros os problemas foram evidenciados, pois existe um sistema de saúde que não os reconhece, portanto não contempla as especificidades geradas pela enfermidade em ações de atenção à saúde (AAFESP/Histórico online s/d ${ }^{-}$grifos nossos) $)^{12}$. 
Iniciou-se, assim, um processo de desvendamento e desmistificação da doença, que implicou a construção de competências específicas para o seu enfrentamento. Na página do "Quem somos" da AAFESP na Web, em 2018, aparecia claramente o objetivo da Associação de se tornar um centro de Referência em Anemia Falciforme autônomo, "voltado para o tratamento dos clientes com anemia falciforme, capacitação de profissionais de saúde e educação, definição, implantação e implementação de políticas públicas”. A ação da entidade abrange também:

Prover por meio dos serviços oferecidos no ambulatório de enfermagem, recursos humanos, materiais, físicos e financeiros que possam subsidiar o desenvolvimento de atividades assistenciais para prevenção e tratamento das pessoas com Anemia Falciforme na competência da enfermagem, estabelecendo parcerias com universidades, convênios e subsídios com instituições públicas e privadas, nacionais e internacionais com a finalidade de estabelecer na América Latina uma cultura de atenção à saúde não medicalizada (AAFESP - site institucional - online s/d., grifos $\operatorname{nossos})^{13}$.

Em 2009, Berenice Kikuchi recebeu o Prêmio Empreendedor Social oferecido pela Folha de S. Paulo e a Fundação Schwab a "líderes de cooperativas, ONGs, empresas sociais (corporações privadas que distribuem o lucro em benefício da sociedade) e pessoas físicas que desenvolveram iniciativas inovadoras e sustentáveis para benefício da coletividade" (UOL, 2009, online). Em matéria publicada sob o título "Enfermeira desvenda doença de origem negra" (BERGEL, 2009, online), Berenice foi apresentada como alguém que desde cedo “[...] aprendeu a se preocupar com questões sociais”[...]; que decidiu ser enfermeira apesar de ter [...] "medo de defunto e de sangue" [...]; que saiu da faculdade [...] "sabendo só que [a anemia falciforme] era uma doença de negros" [...]; e que, [...] "mesmo sem dominar o inglês, visitou a Jamaica e os EUA, onde há centros de referência, para buscar dados e conhecer políticas públicas" [...] relacionadas à doença.

Em 1997, a AAFESP conseguiu que o exame para detectar a anemia falciforme fosse incluído no "teste do pezinho" de recém-nascidos na cidade de São Paulo, direito progressivamente estendido a outros estados. Berenice sonhava em [...] "se embrenhar em órgãos internacionais e alertar o mundo sobre a gravidade da anemia falciforme [...]" (BERGEL, 2009, online), 
ampliando, assim, sua escala de atuação do local para o global. Mas não estava sozinha. Outras vozes somaram-se à dela nesse caminho de desvendamento da doença.

Uma busca simples com a expressão "anemia falciforme" revela a existência de mais de cem teses e dissertações produzidas no País nos últimos anos e quase igual número de artigos científicos, sob o viés de diferentes disciplinas. À época da conclusão deste artigo, Berenice cursava doutorado em Saúde e Desenvolvimento da Região Centro Oeste, na Universidade Federal do Mato Grosso do Sul, estado onde, segundo ela, houve imigração de pessoas com o gene da doença e onde existe uma taxa elevada de traços assintomáticos, que estavam sendo mapeados na pesquisa (MEDEIROS, 2016).

Uma história bem mais pacífica do que a vivenciada pela engenheira civil Fernanda Giannasi, conhecida internacionalmente por sua atuação na luta pelo banimento do amianto no Brasil e no mundo, o que já lhe resultou em ameaças de morte, por contrariar interesses de poderosos grupos econômicos, inclusive estrangeiros. Com especialização em Engenharia de Segurança do Trabalho, Mestrado em Gestão de Empresas e doutorado interrompido em Saúde Pública, Fernanda foi auditora fiscal do Ministério do Trabalho e Emprego e participou do processo de elaboração do projeto que regulamentou o uso do amianto em condições de segurança, em 1991. Paralelamente, coordenava a Rede Virtual Cidadã pelo Banimento do Amianto na América Latina, ligada à Global Ban Asbestos Network, constituída em 1994 por cidadãos de todos os continentes que se dispõem a doar parte de seu tempo, voluntariamente e sem remuneração, em prol da defesa de um mundo sem amianto ${ }^{14}$.

Segundo o Sindicato dos Químicos Unidos de São Paulo, até 2015 o Brasil estava entre os cinco maiores produtores mundiais da fibra do amianto ${ }^{15}$, posição conquistada sobretudo durante a ditadura civil-militar (1964-1985), sob influência de empresas nacionais e multinacionais, à medida que países da Europa iam proibindo a sua exploração. As pressões da indústria do amianto para tirar a engenheira da fiscalização do produto foram tornadas públicas em 2011. Com base em documentos, a jornalista Conceição Lemes (especializada na cobertura de saúde) apontou os vários interesses em jogo e as pressões 
exercidas pela indústria do amianto para constranger os profissionais de saúde pública, por meio de ações judiciais e de intimidações junto a órgãos do alto escalão do governo federal (LEMES, 2011).

A tática de desqualificação da engenheira e do conhecimento que sustenta a atuação da Rede Ban Abestos é exemplificada com uma fala do diretor do Instituto do Crisotila ${ }^{16}$ do Canadá, Denis Hamel, no documentário franco-canadense A morte lenta pelo amianto: "Ela dá declarações mentirosas, exageradas, que prejudicam enormemente os esforços da indústria" (no sentido de sustentar a proposta de "uso controlado" do amianto) $)^{17}$.

No entanto, a tese de que todos os tipos de amianto são cancerígenos e de que não há dose de exposição segura para os seres humanos já foi atestada por instituições técnicas e científicas nacionais e internacionais, tais como: Organização Mundial da Saúde (OMS), Organização Internacional do Trabalho (OIT), Organização Mundial do Comércio (OMC), Agência Internacional para a Pesquisa do Câncer (IARC), Instituto Nacional de Saúde e Pesquisa Médica (INSERM), da França, Instituto Nacional de Saúde Ocupacional (NIOSH), dos EUA, além da Fundação Oswaldo Cruz (Fiocruz) e do Instituto Nacional do Câncer (Inca), no Brasil. Até 2017, mais de 70 países já haviam banido o amianto dos seus territórios. Mas somente em 29 de novembro de 2017 o Supremo Tribunal Federal (STF) proibiu a produção, o comércio e o uso dessa substância no Brasil, embora uma liminar tenha permitido que o estado de Goiás continuasse a utilizá-la até o fim dos embargos jurídicos.

O conhecimento acumulado nesses enfrentamentos com os poderosos do amianto está reunido no repositório do site do Secretariado Internacional da Rede Ban Abestos (IBAS, na sigla em inglês) ${ }^{18}$, que inclui artigos (por ano, desde 2000); relatórios de eventos realizados (conferências, seminários, workshops); regulações; pesquisas científicas; vídeos e recursos de informações úteis sobre os problemas causados pela exposição ao amianto. Há também uma bibliografia especializada selecionada, incluindo uma tese de doutorado (em Serviço Social da PUC-RS) e artigos assinados por Fernanda Giannasi. O título de um deles remete diretamente à posição de contraespecialista exercida pela 
engenheira: "A construção de contrapoderes no Brasil na luta contra o amianto: a globalização por baixo" (grifo nosso).

Este tipo de atuação combinando desvendamento com confronto de saberes, com base em um repertório de conhecimentos socialmente produzidos e distribuídos via tecnologias digitais, é típico das organizações sociais especializadas que atuam em rede, com foco em temáticas pouco valorizadas pelas instituições tradicionais de pesquisa e suas agências de fomento. Este é também o caso da Artigo 19, “organização não-governamental de direitos humanos nascida em 1987, em Londres, com a missão de defender e promover o direito à liberdade de expressão e de acesso à informação em todo o mundo"19. O nome da ONG é uma referência ao $19^{\circ}$ artigo da Declaração Universal dos Direitos Humanos da ONU, que trata dessa questão.

A Artigo 19 atua diretamente em oito países dos cinco continentes (três dos quais na África), e internacionalmente por meio de uma articulação multilateral, como base na premissa de que muitas decisões e acordos que afetam a liberdade de expressão e de informação são realizadas entre governos. Nessa escala, promove ações no âmbito das Nações Unidas, da União Africana, da Organização dos Estados Americanos (OEA), da União Europeia e da Organização para Segurança e Cooperação na Europa ${ }^{20}$.

O Brasil é o único país da América do Sul com escritório próprio, implantado em 2007, na cidade de São Paulo, após dois anos de atividades informais. Sua atuação abrange uma gama de questões jurídicas relacionadas a liberdade de expressão e de informação, funcionamento e operação de meios de comunicação, exercício profissional e demandas de ativistas, dentro "de padrões internacionalmente reconhecidos": advocacy e campanhas; monitoramento, pesquisa e capacitação; legislações e políticas; direitos dos jornalistas, radiodifusão de interesse público, pluralismo midiático e promoção da diversidade.

Mas, ao contrário dos dois exemplos anteriores, o protagonismo da entidade não é exercido por uma pessoa em especial e sim por uma equipe composta por jovens profissionais com formação em Direitos Humanos e Relações Internacionais, incluindo alguma especialização em universidades 
brasileiras e estrangeiras (Estados Unidos, Alemanha, Espanha e Portugal). O discurso na primeira pessoa do plural ilustra esse protagonismo coletivo:

[...] Proporcionamos apoio a vítimas de violações motivadas pelo exercício do direito à liberdade de expressão, discutindo ações protetivas imediatas, prestando auxílio jurídico em casos selecionados e denunciando publicamente a ocorrência de abusos. Além disso, atuamos também sob o viés preventivo, com a produção de materiais e a realização de oficinas que promovam medidas de segurança a comunicadores e defensores de direitos humanos - sempre sem deixar de pressionar o poder público a cumprir suas obrigações nessas áreas (Artigo 19 - site institucional/ missão - online - grifos nossos) ${ }^{21}$.

A atuação da Artigo 19 está dividida em quatro programas institucionais: o Jurídico, denominado Centro de Referência Legal, pautado pelo conceito de litígio "estratégico" ou "paradigmático", visando "[...] dar visibilidade e gerar jurisprudência em torno de casos que representam um contexto mais amplo de violações à liberdade de expressão"[...] $]^{22}$; o de Proteção e Segurança, cuja responsabilidade é “[...] monitorar violações à liberdade de expressão de defensores de direitos humanos e comunicadores [... $]^{23 \% ; ~ o ~ d e ~ A c e s s o ~ a ̀ ~}$ Informação, que "[...] tem como objetivo monitorar e promover o direito ao acesso à informação pública [...]”24; e o de Direitos Digitais, “[...] responsável por monitorar questões relacionadas à liberdade de expressão no ambiente digital [...]", incluindo "[...] a luta contra a vigilância em massa na internet [...] $]^{, 25}$, a defesa da privacidade online e o Marco Civil da Internet. Essas atividades são financiadas pelas fundações Ford, Open Society e Adessium, pelo Fundo das Nações Unidas para a Democracia (UNDF na sigla em inglês), pela Swedish International Development Cooperation Agency (SIDA) e pelo Department for International Development (DFID) ${ }^{26}$.

Entre 2007 e 2017, o escritório brasileiro da Artigo 19 publicou mais de 100 documentos, entre relatórios de análise de dados, coletâneas de artigos de reflexão, sínteses de dados (infográficos), guias e cartilhas de orientação sobre direitos relacionadas a meios de comunicação, sistemas de informação, segurança cibernética, transparência de dados públicos e acesso a informação, todos disponíveis para baixar no site (Artigo 19 - publicações - online) ${ }^{27}$. 
Além de subsidiarem as ações de enfrentamento de advogados, ativistas, jornalistas, comunicadores e cidadãos em geral, esses documentos também embasam o trabalho legislativo no processo regulatório. É o caso do relatório que analisa quatro projetos de lei em tramitação no Congresso Nacional que visam regulamentar o chamado "direito ao esquecimento" no Brasil, e do que alerta para os "[...] riscos dos projetos de lei que pretendem regulamentar o bloqueio ao acesso a sites e aplicativos" (ARTIGO 19, 2017, online).

O subsídio informacional a ações de enfrentamento também se dá por meio de guias e cartilhas que orientam sobre direitos a serem exercidos no dia-adia, como as "[...] diretrizes a serem seguidas por empresas de telecomunicações e provedores de serviços de internet de forma a proteger os direitos humanos de seus usuários e usuárias” [...]; as “[...] orientações sobre o que fazer durante visitas de fiscais da Anatel e agentes da Polícia Federal a rádios comunitárias e em processos criminais abertos contra radialistas comunitários/as" [...]; e "[...] um passo a passo detalhado sobre como montar e regularizar um provedor comunitário de internet" 28 .

Já o desvendamento e o confronto jurídicos podem ser observados em estudos comparativos de âmbito nacional e internacional, como o que "[...] avalia nove bases de dados sobre feminicídios segundo 15 critérios relativos a uma boa prática de dados abertos visando à elaboração de políticas públicas" [...]; o que "[...] analisa como cinco tribunais superiores brasileiros têm julgado casos envolvendo a Lei de Acesso à Informação nos últimos anos" [...]; o que “[...] reúne todos os capítulos sobre o Brasil dos relatórios anuais da Relatoria para a Liberdade de Expressão da OEA, no período de 2005 a 2015" [...]; e o que "[...] analisa a situação do direito à informação pública em 16 países da América Latina e Caribe na última década" [...] (Artigo 19 - publicações 2007-2016 - online) $)^{29}$.

Tratam-se, portanto, de análises produzidas no ritmo da dinâmica de acontecimentos da sociedade brasileira e do contexto internacional, sob uma lógica diferenciada da produção acadêmica, a despeito da base técnico-científica que as orienta. 


\section{Considerações finais}

Este artigo retoma reflexões iniciadas na tese de doutorado sobre informação e contrainformação em redes de ONGs e movimentos sociais (LOPES, 1996), nas quais foram identificados ativistas e profissionais que se contrapunham à "tecnocracia intelectual" e às "elites do conhecimento", em permanente tensão entre o saber teórico e o saber prático, orientados por problemáticas que afetam outros sujeitos e coletividades. Ao longo dos últimos 20 anos, o termo "contraespecialistas", utilizado para qualificar esses atores a partir de Dorothy Nelkin, tem sido alvo de poucos e esparsos estudos, majoritariamente eurocentrados e focados no papel de cientistas, especialistas e ativistas engajados em causas ambientais.

O que se observa, agora, é que essa competência se expandiu para outras temáticas ligadas ao cotidiano dos cidadãos, como saúde, educação, transportes, moradia, comunicação, questões étnicas e de gênero, sob forte influência da cultura dos direitos humanos disseminada desde o início deste século. Permanece, contudo, a característica de um campo de produção de conhecimento "intercampos" socialmente distribuído, no qual cientistas e especialistas assumem responsabilidades com movimentos sociais, comunidades e grupos de cidadãos, atuando abertamente como defensores de suas causas e não raro entrando em conflito conceitual ou epistemológico com especialistas do establishment. Exercem, assim, uma "competência transgressora", com base em uma "ética do desvendamento e do confronto", aqui proposta.

Os três breves estudos de caso que exemplificam essa competência indicam a importância do escopo geográfico da atuação em rede dos contraespecialistas, sobretudo quando as controvérsias e os conflitos atravessam fronteiras e desafiam os argumentos das corporações que atuam transnacionalmente, como faz a Rede Ban Abestos. Também chama a atenção nos três casos a influência que os contraespecialistas e as entidades em que atuam exercem no aparato normativo do Estado: como a conquista da obrigatoriedade do exame para detectar a anemia falciforme em recém-nascidos, a proibição da produção e comercialização do amianto e a atuação para garantia dos direitos à liberdade de expressão e de informação. 
Configuram, assim, o "espaço cívico” a que se refere Braman (2013), como domínios multiescalares onde indivíduos e coletividades podem exercer seus direitos e em relação aos quais os contraespecialistas assumem responsabilidades nas diversas arenas de disputa. Destaque-se, por fim, que apesar de a posição de contraespecialista não ser privilégio do intelectual ou do cientista, como fica evidente no relato sobre o seringueiro Osmarino, observa-se nos três casos a busca por alguma legitimação acadêmica do conhecimento (no sentido de Bourdieu, não de Habermas), desde uma especialização ao doutorado.

A despeito de não ter sido localizado nenhum outro estudo brasileiro ou latino-americano que utilize categorias equivalentes a counter-expert e counterexpertise, os exemplos apresentados neste artigo ilustram o potencial dos contraespecialistas como um ator e a configuração de counter-expertises - com toda a sua complexidade, heterogeneidade de atores sociais, peculiaridades geográficas, e os interesses difusos do Estado e do mercado (inclusive o global). Indicam, ainda, uma relevante lacuna de estudos para ampliar o conhecimento sobre uma gama de conhecimentos e de formas de conhecer "periféricos", que representam um compromisso ético diferenciado daquele que vem sendo normatizado pelas instituições científicas tradicionais. Nesse contexto, o papel da articulação em rede e das tecnologias digitais na democratização do conhecimento, da informação e dos processos decisórios relativos a governança, regulações e formulações de políticas públicas mostra-se vital.

\section{Referências}

AAFESP - ASSOCIAÇÃO DE ANEMIA FALCIFORME DO ESTADO DE SÃO PAULO. Website institucional (online). Apresenta textos sobre a doença e a atuação da entidade. Disponível em: https://www.aafesp.org.br/. Acesso em: 30 maio 2019.

AGUIAR, Sonia. Conhecimento compartilhado e tecnologias societárias em redes de ONGs e movimentos sociais: o papel dos "contraespecialistas". In: JORNADAS LATINOAMERICANAS DE ESTUDIOS SOCIALES DE LA CIENCIA Y LA TECNOLOGÍA (ESOCITE), 7., 2008, Rio de Janeiro. Anais [...]. Rio de Janeiro: NECSOUFRJ, 2008. Disponível em: www.necso.ufrj.br/esocite2008/trabalhos/36273.doc. Acesso em: 22 maio 2018. 

produção de conhecimento socialmente orientado e no confronto de saberes

Sonia Aguiar

AGUIAR, Sonia. Conhecimento e saberes socioambientais: o papel dos "contraespecialistas" nas redes de ONGs e movimentos sociais. In:

ENCONTRO NACIONAL DE PESQUISA EM CIÊNCIA DA INFORMAÇÃO (ENANCIB), 8., 2007a, Salvador. Anais eletrônicos [...]. Salvador: UFBA, 2007. Disponível em: https://bit.ly/2Pay51Q. Acesso em: 30 maio 2018.

AGUIAR, Sonia. Formas de organização e enredamento para ações sociopolíticas. Informação \& Informação, Londrina (PR), v. 12, n. esp. 2007 b. Disponível em: http://www.uel.br/revistas/uel/index.php/informacao/article/view/1776/1514. Acesso em: 02 jun. 2018.

ARTIGO 19 - Website institucional (online). Apresenta textos sobre direitos humanos, direito à comunicação e democratização da informação. Disponível em: http://artigo19.org/. Acesso ao longo do mês de maio de 2018.

ARTIGO 19. Bloqueios de sites e aplicativos no Brasil: subsídios ao debate legislativo. São Paulo (SP): Artigo 19, 2017. Disponível em: https://artigo19.org/blog/2017/12/07/regulamentacao-de-bloqueio-a-sites-eaplicativos-e-tema-de-publicacao-da-artigo-19/. Acesso em: 22 maio 2018.

BÄCKSTRAND, Karin. Scientisation vs. civic expertise in environmental governance: eco-feminist, ecomodern and post-modern responses. Abingdon (UK): Environmental Politics, v. 13, n. 4, p. 695-714, 2004.

BECK, Ulrich. Critical theory of world risk society: a cosmopolitan vision. S.1., Constellations, v. 16, n. 1, 2009. Disponível em:

https://www.jus.uio.no/smr/om/aktuelt/arrangementer/2015/urlich-beck-

cosmopolitan-view.pdf. Acesso em: 22 maio 2018.

BECK, Ulrich. Liberdade ou capitalismo: conversa com Johannes Willms. São Paulo: Unesp, 2002.

BERGEL, Mariana. Enfermeira desvenda doença de origem negra.

Empreendedor Social 2009. São Paulo, 2009 (online). Disponível em: http://www2.uol.com.br/empreendedorsocial/2006-berenice.shtml. Acesso em: 26 maio 2018.

BIRD, Stephanie J. Socially responsible science is more than "good science". Washington, DC: Journal of Microbiology \& Biology Education, v. 15, n. 2, p. 169-172, dec. 2014. Disponível em:

http://www.ncbi.nlm.nih.gov/pmc/articles/PMC4278471/. Acesso em: 26 maio 2018.

BOURDIEU, Pierre. Os usos sociais da ciência: por uma Sociologia do campo científico. São Paulo: Unesp, 2004. 
BRAMAN, Sandra. "We are Bradley Manning": information policy, the legal subject, and the WikiLeaks Complex. Los Angeles, CA: International Journal of Communication, v. 8, p. 2603-2618, 2014. Disponível em: http://ijoc.org/index.php/ijoc/article/download/2668/1242. Acesso em: 03 jun.2018.

BRAMAN, Sandra. The geopolitical vs. the network political: Internet designers and governance. Oxford, UK: International Journal of Media \& Cultural Politics, v. 9, n. 3, p. 277-296, 2013. Disponível em:

http://people.tamu.edu/ braman/bramanpdfs/88_geopol.pdf. Acesso em: 22 maio 2018.

BRAND, Ralf; KARVONEN, Andrew. The ecosystem of expertise: complementary knowledges for sustainable development. Abingdon, UK: Sustainability: Science, Practice and Policy, v.3, n.1, p. 21-31, 2007.

CAVALCANTI, Juliana Manzoni; MAIO, Marcos Chor. Entre negros e miscigenados: a anemia e o traço falciforme no Brasil nas décadas de 1930 e 1940. História, Ciências, Saúde-Manguinhos, Rio de Janeiro, v. 18 n. 2, abr../jun. 2011. Disponível em: http://dx.doi.org/10.1590/S010459702011000200007. Acesso em 17 out. 2018.

EDEN, Sally; DONALDSON, Andrew; WALKER, Gordom. Green groups and grey areas: scientific boundary-work, nongovernmental organizations, and environmental knowledge. Sage Journals, s.l.: Environment and Planning, v. 38, n. 6, p. 1061-1076, 2006.

FRANKEL, Mark S. Science as a socially responsible community. s.1.: The Poynter Center Indiana University, 1994 (individual paper).

FREITAS, Carlos Machado de; PORTO, Marcelo Firpo de Souza. Discutindo o papel da ciência frente à justiça ambiental. ENCONTRO DA ANPPAS (Associação Nacional de Pesquisa e Pós Graduação em Ambiente e Sociedade), 2., 2004, Indaiatuba. Anais eletrônicos [...]. Indaiatuba: ANPPAS, 2004. Disponível em: http://www.anppas.org.br/encontro_anual/encontro2/GT/GT17/gt17_marcelo_p orto.pdf. Acesso em: 03 jun.2018.

HABERMAS, Jürgen. O papel da sociedade civil e da esfera pública política. In: HABERMAS, Jürgen. Direito e democracia: entre facticidade e validade. v. 2. Rio de Janeiro: Tempo Brasileiro, 1997. p. 57-121.

HANSEN, Tom Børsen. Academic and social responsibility of scientists. In: s.l.: Journal on Science and World Affairs, v. 2, n. 2, p.71-92, 2006. Disponível em: http://www.scienceandworldaffairs.org/PDFs/Vol2No2_BorsenHansen.pdf. Acesso em: 03 jun. 2018. 

produção de conhecimento socialmente orientado e no confronto de saberes

Sonia Aguiar

HERCULANO, Selene O. O campo do ecologismo no Brasil: o Fórum das ONGs. In: REIS, E.; ALMEIDA, M. E.; FRY, P. (orgs.). Política e cultura; visões do passado e perspectivas contemporâneas. São Paulo: Hucitec/Anpocs, 1996. p. $91-126$.

LEMES, Conceição. As pressões para tirar Fernanda Giannasi da fiscalização do amianto. Viomundo, s.1. 24 mar. 2011 (online). Disponível em: https://www.viomundo.com.br/denuncias/as-pressoes-para-tirar-fernandagiannasi-da-fiscalizacao-do-amianto.html. Acesso em: 03 jun. 2018.

LOPES, Sonia Aguiar. A teia invisível: informação e contra-informação nas redes de ONGs e movimentos sociais. 1996. 2 v. $281 \mathrm{fls}$. Tese (Doutorado em Comunicação/ Ciência da Informação) - Escola de Comunicação, Universidade Federal do Rio de Janeiro/Ibict, Rio de Janeiro, 1996. Disponível em: https://bit.ly/2ClUT82. Acesso em: 03 jun. 2018.

MEDEIROS, Gesiane. Oficina alerta sobre a Anemia Falciforme. Corumbá (MS): Capital do Pantanal, 11/04/2016 (online). Disponível em: http://www.capitaldopantanal.com.br/geral/oficina-alerta-sobre-a-anemiafalciforme/514859/. Acesso em: 03 jun. 2018.

NELKIN, Dorothy. The political impact of technical expertise. Social Studies of Science, New York, v. 5, n. 1, p. 35-54, fev. 1975.

NELKIN, Dorothy. Science and technology policy and the democratic process. In: TEICH, Albert H. (ed.) Technology and man's future. 3. ed. New York: St. Martin's Press, 1981. p. 270-293.

NEVES-GRAÇA, Katja. Politics of environmentalism and ecological knowledge at the intersection of local and global processes. S.l. Journal of Ecological Anthropology, v. 10, p. 19-32, 2006. Disponível em: http://scholarcommons.usf.edu/cgi/viewcontent.cgi?article $=1046 \&$ context=jea . Acesso em: 03 jun. 2018.

NOWOTNY, Helga. Transgressive Competence: The Narrative of Expertise. S.1. European Journal of Social Theory, v. 3, n. 1, p. 5-21, 2000. Disponível em: https://pdfs.semanticscholar.org/8c04/47ee9aca682c027f7cc2893828bb1fbcc1ff. pdf. Acesso em: 23 jun. 2018.

PETERSEN, Paulo; ALMEIDA, Silvio G. Rincões transformadores: trajetória e desafios do movimento agroecológico brasileiro. In: ROMANO, J. O. et al (org.). Olhar crítico sobre participação e cidadania: a construção de uma governança democrática e participativa a partir do local. São Paulo/Rio de Janeiro: Expressão Popular/Actionaid, v. 2, 2007. p. 65-111. 

produção de conhecimento socialmente orientado e no confronto de saberes

Sonia Aguiar

RESNIK, David B. J. D.; ELLIOTT, Kevin C. The ethical challenges of socially responsible science. S.1. Accountability in Research: Policies and Quality Assurance, v. 23, n. 1, p. 31-46, 2016.

SCHNEIDER, Mycle. The citizen science concept: the role of independent and counter-expertise. Rethinking nuclear energy and democracy after 09/11, Basel, Ubiquity Press, 2002. Disponível em: https://www.ubiquitypress.com/site/chapters/10.5334/bbf.o/download/919/. Acesso em: 03 jun. 2018.

TATENHOVE, Jan P. M. van; LEROY, Pieter. Environment and participation in a context of political modernisation. S.l. Environmental Values, v. 12, p. 155-74, 2003.

TOPÇU, Sezin. Confronting nuclear risks: counter-expertise as politics within the French Nuclear Energy Debate. S.1. Nature and Culture, v. 3, n. 2, p. 225245, Autumn 2008. Disponível em:

http://www.environnement.ens.fr/IMG/Topcu-

Nature\%20and\%20Culture(1).pdf. Acesso em: 03 jun. 2018.

UOL. Empreendedor Social: O que é. S.Paulo (SP): UOL, 2009. Disponível em: http://www2.uol.com.br/empreendedorsocial/oquee.shtml. Acesso em 15 maio 2018.

WELSH, Ian; PLOWS, Alexandra; EVANS, Robert. Another science for another world?: Science and genomics at the London Social Forum. Cardiff University School of Social Science, Working Paper Series. Paper 70, 2005.

WOODHOUSE, E. J.; NIEUSMA, Dean. Democratic expertise: integrating knowledge, power, and participation. In: HISSCHEMOLLER, Matthijs et al. (org.). Knowledge, power and participation in environmental policy analysis. Policy Studies Review Annual, New Brunswick and London: Transaction Publishers, 2001. v. 12. p. 73-96.

\title{
The transgressive competence of counter-experts in the production of socially oriented knowledge and in the confrontation of know-how
}

\begin{abstract}
A literature sparsely developed since the 1970s, especially in the European context, discusses the social responsibility of scientists and scientific institutions in face of the controversies surrounding human rights and risk situations for citizens. Based on it, this paper identify informal instances and actors which produce knowledge socially oriented and institutionally distributed, seeking to influence decision-making processes of the State, the market and society with the support of digital networking. Such epistemological option is
\end{abstract}


motivated by what we propose to call "ethics of uncovering and confrontation", associated with what science sociologist Helga Nowotny called "transgressive competence", typical of counter-experts.

Keywords: Counter-experts. Counter-expertise. Transgressive competence. Knowledge production. Scientific controversies.

Recebido: 07/06/2018 Aceito: 16/11/2018

${ }^{1}$ Um esboço das ideias que guiaram este artigo foi originalmente apresentado no IV Seminário de Estudos da Informação, com o tema "Ética e políticas da informação: agentes, regimes e mediações", realizado em setembro de 2015, na Universidade Federal Fluminense, sob a coordenação da profa. Nélida Gonzalez de Gomez, a quem agradeço pelas inúmeras inspirações intelectuais.

2 "Em meados dos anos 1990, no início dos debates sobre a adoção de políticas de ação afirmativa no Brasil, a anemia falciforme adquiriu visibilidade ao ser considerada doença genética específica da 'raça negra', o que legitimaria a criação de políticas voltadas para a 'saúde da população negra' (Maio, Monteiro, 2005; Fry, 2005). O interesse pelo tema permitiu verificar a ausência de estudos históricos que examinem a produção médica brasileira referente ao binômio anemia falciforme e raça negra" (CAVALCANTI; MAIO, 2011, online).

${ }^{3} \mathrm{O}$ termo indica uma ação coletiva de caráter político embasada em valores e racionalidades de interesse público ou de solidariedade com grupos sociais desfavorecidos pelo Estado. Envolve "promoção de direitos", quando visa ampliar o espectro de direitos já conquistados, ou "defesa de direitos", quando estes estão sendo violados ou sob ameaça (RODRIGUES, 1999; AZEVEDO, 2003, apud AGUIAR, 2007b, online).

4 Accountability diz respeito ao sentido moral e normativo da "responsabilidade" de prestar contas de obrigações legais, ou moralmente ou contratualmente assumidas, por manifestação de vontade, por dever de ofício ou do Estado; ou ainda para responder por atos de violação de direitos de outrem.

${ }^{5}$ Vale ressaltar que a discussão empreendida neste artigo não contempla a noção de citizen science, utilizada nos EUA para se referir a pesquisas colaborativas entre cientistas e voluntários, visando particularmente (mas não apenas) a ampliação de oportunidades de coleta de dados científicos e o provimento de acesso à informação científica a membros de uma comunidade. Ver em: http://www.birds.cornell.edu/citscitoolkit/about/definition.

${ }^{6}$ Tradução livre para: This includes an involuntary selfcriticism of science in the conflict between experts and counter-experts as well as the inability to redeem in an anticipatory way promises of security in the face of the "unknown unknowns", hence of the inability-to know.

${ }^{7}$ Campus avançado da Universidade Federal do Acre (UFAC), no Alto Juruá, que em 2006 sediou a reunião regional da Sociedade Brasileira para o Progresso da Ciência (SBPC).

${ }^{8}$ Projeto de manejo na primeira floresta pública estadual do Acre.

9 "Sociedade civil" é aqui pensada nos termos propostos por Gramsci, como um Estado Ampliado, em que atores sociais diferentes, em associações voluntárias plurais, lutam por hegemonia e consenso, por meio de uma guerra de posição, conforme Herculano (1996, p. 91).

10 Os documentos utilizados para a análise foram extraídos, majoritariamente, dos sites institucionais onde atuam os contra-especialistas que protagonizam os estudos de casos.

11 "A Anemia Falciforme, com prevalência média de 1 entre 380 nascidos vivos, nos afrodescendentes nas Américas é doença genética, incurável e com alta morbimortalidade. A característica principal da Anemia Falciforme é a deformação que causa na membrana dos glóbulos vermelhos do sangue. Os glóbulos vermelhos são células arredondadas e elásticas que 
passam facilmente por todo o sistema circulatório. Existem milhões destas células circulando por todo o corpo". Ver em: http://www.aafesp.org.br/o-queanemia-falciforme.shtml.

${ }^{12}$ Disponível em: http://www.aafesp.org.br/historico-aafesp.shtml. Acesso em 15 maio 2018

${ }_{14}^{13}$ Disponível em: https://aafesp.org.br/index.php\#AAFESP. Acesso em 30 maio 2019.

${ }^{14}$ Segundo a Associação Brasileira dos Expostos ao Amianto (Abrea), que tem entre seus objetivos: "Conscientizar à população em geral, trabalhadores e opinião pública, sobre os riscos do amianto e existência de produtos e tecnologias substitutas". Ver em: http://www.abrea.org.br/.

15 "O amianto - utilizado na fabricação de caixas d'água, pastilhas para freios, telhas, roupas antichamas e muitos outros produtos - provoca graves doenças como asbestose, câncer de pulmão, mesotelioma (câncer de pleura) e cânceres na laringe, estômago, fígado, pâncreas, rins, ovários, cérebro e sangue. Geralmente incuráveis, essas doenças têm como principais sintomas dores nas costas, quadros recorrentes de pneumonia, tosse, cansaço e limitação aos esforços." Disponível em: www.quimicosunificados.com.br/1142/a-historia-de-lutas-da-drafernanda-giannai/. Acesso em 23 abr. 2018.

${ }^{16}$ Subgrupo de minerais asbestiformes conhecido como "amianto branco".

${ }^{17}$ Em 2005, o filme dirigido por Sylvie Deleule recebeu o prêmio principal do Festival Internacional de Cinema Ambiental (FICA), realizado há décadas em Goiás, onde está situada a maior mina de amianto do País.

${ }^{18}$ International Ban Asbestos Secretariat http://www.ibasecretariat.org/.

${ }^{19}$ Apresentação do site institucional da ONG Artigo 19, disponível em: https://artigo19.org/aorganizacao/. Acesso em 23 abr 2018.

${ }^{20}$ Article 19 - Where we work - Disponível em: https://www.article19.org/where-we-work/. Acesso em 23 abr 2018.

${ }^{21}$ Disponível em: https://artigo19.org/missao/. Acesso em 23 abr 2018.

${ }^{22}$ Disponível em: https://artigo19.org/centro-de-referencia/. Acesso em 23 maio 2018.

${ }^{23}$ Disponível em: https://artigo19.org/protecao/. Acesso em 23 maio 2018.

${ }^{24}$ Disponível em: https://artigo19.org/acesso/. Acesso em 23 maio 2018.

${ }^{25}$ Disponível em: https://artigo19.org/direitos-digitais/. Acesso em 23 maio 2018.

${ }^{26}$ Informações coletadas em maio de 2018 em http://artigo19.org/.

${ }^{27}$ Disponível em: https://artigo19.org/blog/category/publicacoes/. Acesso em 23 maio 2018.

${ }^{28}$ Disponível em: https://artigo19.org/blog/category/publicacoes/. Acesso em 23 maio 2018.

${ }^{29}$ Disponível em: https://artigo19.org/blog/category/publicacoes/. Acesso em 23 maio 2018. 